Title:

Hydrothermal synthesis and study of an inorganic-organic hybrid vanadate of a nickel( II ) coordination complex with pyrazine, $\mathrm{Ni}_{3}\left(\mathrm{C}_{4} \mathrm{H}_{4} \mathrm{~N}_{2}\right)_{3}\left(\mathrm{~V}_{8} \mathrm{O}_{23}\right)$

Larrea ES, Mesa JL, Arriortua MI.

Materials Research Bulletin 46(6) : 845-849 (2011)

This work is made available online in accordance with publisher policies. To see the final version of this work please visit the publisher's website. Access to the published online version may require a subscription.

Link to publisher's version:

http://dx.doi.org/10.1016/j.materresbull.2011.02.033

Copyright statement: $\odot<2011>$ Elsevier Ltd. Full-text reproduced in accordance with the publisher's self-archiving policy.

This manuscript version is made available under the CC-BY-NC-ND 4.0 license http://creativecommons.org/licenses/by-nc-nd/4.0

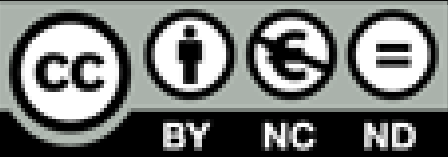




\title{
Hydrothermal Synthesis and Study of an Inorganic-Organic Hybrid Vanadate of a Nickel(II) Coordination Complex with Pyrazine, $\mathrm{Ni}_{3}\left(\mathrm{C}_{4} \mathrm{H}_{4} \mathbf{N}_{2}\right)_{3}\left(\mathrm{~V}_{8} \mathrm{O}_{23}\right)$
}

\author{
Edurne S. Larrea ${ }^{1}$, José L. Mesa ${ }^{2} *$ and María I. Arriortua ${ }^{1}$. \\ ${ }^{1}$ Dpto. de Mineralogía y Petrología and ${ }^{2}$ Dpto. de Química Inorgánica, Facultad de \\ Ciencia y Tecnología, Universidad del País Vasco/Euskal Herriko Unibertsitatea, \\ UPV/EHU, Apdo. 644, E-48080 Bilbao, Spain.
}

\begin{abstract}
The three-dimensional hybrid compound $\mathrm{Ni}_{3}\left(\mathrm{C}_{4} \mathrm{H}_{4} \mathrm{~N}_{2}\right)_{3}\left(\mathrm{~V}_{8} \mathrm{O}_{23}\right)$ has been synthesized by mild hydrothermal methods under autogenous pressure at $170{ }^{\circ} \mathrm{C}$. The structure of the phase is stable until $380{ }^{\circ} \mathrm{C}$. The removal of the pyrazine molecules from the structure induces its collapse. The IR spectrum shows the vibration modes of the pyrazine molecule and those of the $\left[\mathrm{VO}_{4}\right]^{3-}$ groups. A UV-visible spectrum shows the characteristic bands of the $\mathrm{Ni}(\mathrm{II}) \mathrm{d}^{8}$-high-spin cation in a slightly distorted octahedral coordination. Magnetic measurements indicate the existence of antiferromagnetic interactions that can be fitted with a chain model to give $\mathrm{g}=2.31, \mathrm{~J} / \mathrm{k}=-5.3$, and $\mathrm{zJ} / \mathrm{k}=$ -5.5 .

Keywords: $\quad$ Hydrothermal $\quad$ Synthesis; $\quad$ Spectroscopy; Magnetism

*Corresponding author:

e-mail: joseluis.mesa@ehu.es; Phone: 34-946015523; Fax: 34-946013500
\end{abstract}




\section{Introduction}

Hybrid inorganic-organic materials have become a major research topic in materials science because of their ability to exhibit functionality from both their inorganic and organic components [1]. This class of materials is of great interest because of their potential applications in medicine [2], sensing [3], and catalysis [4], among others.

In the last few years, several synthetic approaches have been followed to obtain hybrid materials. One of these approaches involves the combination of metal oxides with organic ligands along with other heterometallic centers. This approach has yielded an impressive class of organic-transition metal oxide hybrids constructed from molybdenum and vanadium oxides and metal-organic complexes [5].

Interest in vanadium oxides stems from the redox chemistry associated with this metal and the structural variety of substructures that can be obtained. Depending on the oxidation state, vanadium can be found in various coordination environments, ranging from the ideal octahedron for the oxidation state three to the tetrahedron for the oxidation state five. It can also be found in the distorted octahedron, the square-based pyramid and the trigonal bipyramid (oxidation states four and five) [6]. The polymerization of these coordination polyhedra gives rise to a wide variety of substructures, such as clusters, rings, chains, layers, and 3-D frameworks [7]. The polymerization degree of the vanadium substructures can be controlled by the synthetic conditions [8].

With regard to the metal-organic moiety, it can be discrete or polymeric (1-, 2- or 3-D), depending on the organic ligand used and the coordination preferences of the metal. In our research work, we have used first-row transition metals with a preferential coordination of six and two types of organic ligands: aliphatic and aromatic amines. When using aliphatic amines or aromatic amines with chelating properties (2,2'bipyridine, phenantroline), discrete metal-organic units are obtained [9]. Whereas, if aromatic amines with bridging properties such as pyrazine, 4,4'-bipyridine or 1,2-di(4pyridil)ethene are used, extended metal-organic frameworks are obtained [10].

It is obvious that the election of the metal, the organic ligand and the synthesis conditions determine whether the structures obtained have more or less complexity.

In this work, we report the characterization and properties of a hybrid vanadate with sixcoordinated nickel(II) and pyrazine, which acts as a bridging ligand, $\mathrm{Ni}_{3}\left(\mathrm{C}_{4} \mathrm{H}_{4} \mathrm{~N}_{2}\right)_{3}\left(\mathrm{~V}_{8} \mathrm{O}_{23}\right)$. The structure of this phase had been studied previously by our 
research group, but we were unable to obtain the product as a pure phase [11]. Here, we describe the separation method used to purify the phase to characterize it, and we report on the thermal, spectroscopic and magnetic behaviors of the material.

\section{Experimental}

\subsection{Synthesis and Characterization}

$\mathrm{Ni}_{3}\left(\mathrm{C}_{4} \mathrm{H}_{4} \mathrm{~N}_{2}\right)_{3}\left(\mathrm{~V}_{8} \mathrm{O}_{23}\right)$ has been synthesized using mild solvothermal conditions using PTFE (poly-tetrafluoroethylene) reactors. In a typical synthesis, $100 \mathrm{mg}(0.34 \mathrm{mmol})$ of $\mathrm{Ni}\left(\mathrm{NO}_{3}\right)_{2} \cdot 6 \mathrm{H}_{2} \mathrm{O}, 41.93 \mathrm{mg}(0.34 \mathrm{mmol})$ of $\mathrm{NaVO}_{3}$ and $27.23 \mathrm{mg}(0.34 \mathrm{mmol})$ of pyrazine (pz) were added to $30 \mathrm{ml}$ of distilled water, resulting in a $\mathrm{pH}$ of 5.5. This $\mathrm{pH}$ was decreased to 3 by adding a few drops of a $1 \mathrm{M}$ solution of $\mathrm{HCl}$. After maintaining the reactors for five days at $170^{\circ} \mathrm{C}$, a mixture of green prismatic crystals and some unidentified yellow powder was obtained. Crystalline product was separated from the powder, washed with distilled water and acetone, and dried at room temperature.

The powder X-Ray diffraction analysis of the crystals shows the presence of two phases, the one given in the title and $\mathrm{Ni}_{2}\left(\mathrm{C}_{4} \mathrm{H}_{4} \mathrm{~N}_{2}\right)\left(\mathrm{V}_{4} \mathrm{O}_{12}\right)\left(\mathrm{H}_{2} \mathrm{O}\right)_{2}$ [11]. Several trials were conducted with varying synthesis conditions $(\mathrm{pH}$, reagent concentrations, molar ratio, reaction temperature and time and reagents) to obtain the title compound as a single product. However, it always appears together with crystals of $\mathrm{Ni}_{2}\left(\mathrm{C}_{4} \mathrm{H}_{4} \mathrm{~N}_{2}\right)\left(\mathrm{V}_{4} \mathrm{O}_{12}\right)\left(\mathrm{H}_{2} \mathrm{O}\right)_{2}$. For this reason, we proceeded to separate both phases by taking into account the advantage of the different physical properties of both phases, specifically of the different density values. The density of both phases were measured by the flotation method [12], using a mixture of $\mathrm{CH}_{2} \mathrm{I}_{2}\left(3.222 \mathrm{~g} / \mathrm{cm}^{3}\right)$ and $\mathrm{CH}_{2} \mathrm{Cl}_{2}(1.325$ $\left.\mathrm{g} / \mathrm{cm}^{3}\right)$. The density was $2.41(1) \mathrm{g} / \mathrm{cm}^{3}$ for $\mathrm{Ni}_{3}\left(\mathrm{C}_{4} \mathrm{H}_{4} \mathrm{~N}_{2}\right)_{3}\left(\mathrm{~V}_{8} \mathrm{O}_{23}\right)$ and $2.70(1) \mathrm{g} / \mathrm{cm}^{3}$ for $\mathrm{Ni}_{2}\left(\mathrm{C}_{4} \mathrm{H}_{4} \mathrm{~N}_{2}\right)\left(\mathrm{V}_{4} \mathrm{O}_{12}\right)\left(\mathrm{H}_{2} \mathrm{O}\right)_{2}$. The same liquids were used to prepare a mixture with a density of approximately $2.55 \mathrm{~g} / \mathrm{cm}^{3}$. The mixture of crystals was added to the prepared solution. After a short time, the crystals of the denser phase, $\mathrm{Ni}_{2}\left(\mathrm{C}_{4} \mathrm{H}_{4} \mathrm{~N}_{2}\right)\left(\mathrm{V}_{4} \mathrm{O}_{12}\right)\left(\mathrm{H}_{2} \mathrm{O}\right)_{2}$, were at the bottom and the crystals of the title compound were floating at the top. The crystals of $\mathrm{Ni}_{3}\left(\mathrm{C}_{4} \mathrm{H}_{4} \mathrm{~N}_{2}\right)_{3}\left(\mathrm{~V}_{8} \mathrm{O}_{23}\right)$ were then easily removed from the liquid, washed with distilled water and acetone and left to dry at room temperature. The isolated crystals were observed carefully under a polarizing microscope to remove any remaining crystals of the other phase. 
The amounts of nickel and vanadium in $\mathrm{Ni}_{3}\left(\mathrm{C}_{4} \mathrm{H}_{4} \mathrm{~N}_{2}\right)_{3}\left(\mathrm{~V}_{8} \mathrm{O}_{23}\right)$ were measured by inductively coupled plasma-atomic emission spectrometry (ICP-AES), and C, N and $\mathrm{H}$ were measured by elemental analysis. The following values were calculated (\%): $\mathrm{Ni}$, 14.8; V, 34.2; C, 12.1; N, 7.0; H, 1.0. The following values were found experimentally (\%): Ni, 14.3(2); V, 33.9(1); C, 11.8(1); N, 6.8(1); H, 0.9(1).

\subsection{Powder X-ray diffraction}

To evaluate the pureness of the isolated phase, powder X-Ray diffraction was performed. The sample was pounded with an agate mortar until homogenized. The X-ray diffraction data were collected with a BRUKER D8 Advance Vario equipped with a primary monochromator and a solid-state detector SolX with an energy discrimination window optimized for copper $K \alpha_{1}$. The diffracted intensities were collected from $6^{\circ}$ to $100^{\circ}$ in $2 \theta$, with a step size of $0.015^{\circ}$ and a measuring time of $30 \mathrm{~s}$ per step.

After the Rietveld analysis $\left(\chi^{2}=3.50\right)$, the cell parameters obtained were $\mathbf{a}=$ 8.5074(3) $\AA, b=9.0726(3) \AA, c=12.530(3) \AA, \alpha=70.997(2)^{\circ}, \beta=83.488(2)^{\circ}$, and $\gamma=$ $61.229(2)^{\circ}$, in agreement with the values obtained by the single-crystal X-Ray diffraction method [11]. The good fitting achieved for the experimental pattern (Fig. 1) together with the cell parameters after the refinement proved that the isolated phase was pure and could be used for the subsequent characterization.

Figure 1

\subsection{Physicochemical characterization techniques}

Thermogravimetric analysis (TGA) was performed under synthetic air on a NETZSCH STA $449 \mathrm{C}$ thermobalance. A crucible containing approximately $20 \mathrm{mg}$ of sample was heated at $5{ }^{\circ} \mathrm{C} \cdot \mathrm{min}^{-1}$ in the temperature range $30^{\circ}-500{ }^{\circ} \mathrm{C}$. The thermal study was completed using time-resolved X-ray diffractometry (thermodiffractometry). A BRUKER D8 Advance Vantec diffractometer ( $\mathrm{Cu}-\mathrm{K} \alpha$ radiation) equipped with a variable-temperature stage (Anton Paar HTK2000) with a Pt sample holder was used in the experiment. The powder patterns were recorded every $10{ }^{\circ} \mathrm{C}$ from room temperature 
to $500{ }^{\circ} \mathrm{C}$ in $2 \theta$ steps of $0.01667^{\circ}$ in the $5 \leq 2 \theta \leq 38^{\circ}$ range, with $0.1 \mathrm{~s}$ per step. The IR spectrum (KBr pellet) was obtained with a Nicolet FT-IR 740 spectrophotometer in the $4000-400 \mathrm{~cm}^{-1}$ range. The ultraviolet-visible spectrum of the powdered sample (diffuse reflectance) was registered at room temperature in the $200-17800 \mathrm{~nm}$ range on a Varian Cary 5000 spectrometer. Magnetic measurements were performed in a Quantum Design SQUID MPMS-7T magnetometer. The magnetic susceptibility data were obtained on powdered samples in the temperature range of $2.0-300 \mathrm{~K}$ in a magnetic field of $1 \mathrm{kG}$, first after zero-field cooling (ZFC) and next after field cooling (FC).

\section{Results and Discussion}

\subsection{Thermal Behavior}

A thermal behavior study was conducted by using thermogravimetric (TG) and thermodiffractometric analyses. The TG curve shows only one mass loss, which was associated with an exothermic process. This process occurs between 405 and $440{ }^{\circ} \mathrm{C}$. In this temperature range, $20.1 \%$ of the mass is lost, which represents the theoretical weight of the pyrazine molecule. The product of the thermal decomposition was analyzed by powder X-ray diffraction, and it consisted of a mixture of a nickel(II) vanadate, $\mathrm{Ni}\left(\mathrm{V}_{2} \mathrm{O}_{6}\right)$ (S.G. P-1, $\mathrm{a}=7.128 \AA, \mathrm{b}=8.820 \AA$, $\mathrm{c}=4.793 \AA, \alpha=90.24^{\circ}, \beta=$ $94.10^{\circ}, \gamma=102.15^{\circ}$ ) [13], and vanadium(V) oxide, $\mathrm{V}_{2} \mathrm{O}_{5}$ (S.G. $\mathrm{Pmn} 2_{1}, \mathrm{a}=11.503 \AA$, $\mathrm{b}=$ $4.369 \AA$, c= $3557 \AA$ ) [14]. Taking into account these results, the decomposition reaction must be the following:

$\mathrm{Ni}_{3}\left(\mathrm{C}_{4} \mathrm{H}_{4} \mathrm{~N}_{2}\right)_{3}\left(\mathrm{~V}_{8} \mathrm{O}_{23}\right) \stackrel{T \uparrow}{\longrightarrow} \quad 3 \mathrm{Ni}\left(\mathrm{V}_{2} \mathrm{O}_{6}\right)_{(\mathrm{s})}+\mathrm{V}_{2} \mathrm{O}_{5(\mathrm{~s})}+3 \mathrm{C}_{4} \mathrm{H}_{4} \mathrm{~N}_{2(\mathrm{~g})}$.

The thermodiffractometric study (Figure 2) shows that the structure of the phase is stable until $380{ }^{\circ} \mathrm{C}$. During heating, the cell volume of $\mathrm{Ni}_{3}\left(\mathrm{C}_{4} \mathrm{H}_{4} \mathrm{~N}_{2}\right)_{3}\left(\mathrm{~V}_{8} \mathrm{O}_{23}\right)$ increases by $0.84 \%$ before the collapse of the structure. Taking into account the stability temperature and the thermogravimetric data, the collapse of the structure is due to the removal of the pyrazine. As the maxima of the hybrid vanadate disappear, the maxima of the decomposition product begin to appear. These maxima match with those observed after the thermogravimetric decomposition. 
"Figure 2"

\subsection{Spectroscopic Properties}

The IR spectrum shows three main absorption regions in the $4000-400 \mathrm{~cm}^{-1}$ range. First, the group of weak bands absorbing between 3115 and $2850 \mathrm{~cm}^{-1}$ are due to the stretching vibration of the $\mathrm{C}-\mathrm{H}$ bonds of the pyrazine. Between 1420 and $1065 \mathrm{~cm}^{-1}$, the stretching vibration of the $\mathrm{C}-\mathrm{C}$ and the $\mathrm{C}-\mathrm{N}$ bonds of the aromatic ring can be observed. In the third region, from 1000 to $475 \mathrm{~cm}^{-1}$, a group of strong bands due to the absorption of the $\mathrm{V}-\mathrm{O}$ bonds are registered. Because the vanadate oxoanion has different $\mathrm{V}-\mathrm{O}$ bond distances depending on the connectivity of the oxygen atoms, several absorption bands appear in this range. At $1000 \mathrm{~cm}^{-1}$, the band caused by the terminal V-O bond is observed. Between 970 and $910 \mathrm{~cm}^{-1}$, a series of bands that can be attributed to the antisymmetric stretching vibration of the $\mathrm{V}-\mathrm{O}(-\mathrm{V})$ bonds is observed. The symmetric stretching vibrations of these bonds appear at $640 \mathrm{~cm}^{-1}$. The bands due to the $\mathrm{V}-\mathrm{O}(-\mathrm{Ni})$ bonds appear as a group of four bands between 860 and $805 \mathrm{~cm}^{-1}$ for the antisymmetric stretching, and another group of four bands in the range of $535-475 \mathrm{~cm}^{-1}$ is due to the symmetric vibrations.

The UV-visible spectrum of $\mathrm{Ni}_{3}\left(\mathrm{C}_{4} \mathrm{H}_{4} \mathrm{~N}_{2}\right)_{3}\left(\mathrm{~V}_{8} \mathrm{O}_{23}\right)$ shows two absorption bands at 8900 and $15400 \mathrm{~cm}^{-1}$ and a shoulder at $12250 \mathrm{~cm}^{-1}$. At $3000 \mathrm{~cm}^{-1}$, the charge transfer band appears. According to the energy level diagram [15] of a high spin $\mathrm{d}^{8}$ system, there are three spin allowed transitions between the ground state ${ }^{3} \mathrm{~A}_{2 \mathrm{~g}}\left({ }^{3} \mathrm{~F}\right)$ and the excited states $\left.{ }^{3} \mathrm{~T}_{2 \mathrm{~g}}{ }^{3} \mathrm{~F}\right),{ }^{3} \mathrm{~T}_{1 \mathrm{~g}}\left({ }^{3} \mathrm{~F}\right)$ and ${ }^{3} \mathrm{~T}_{1 \mathrm{~g}}\left({ }^{3} \mathrm{P}\right)$. In addition, it is common to observe two spin forbidden bands because of the electronic transitions to the ${ }^{1} \mathrm{E}_{\mathrm{g}}\left({ }^{1} \mathrm{D}\right)$ and ${ }^{1} \mathrm{~T}_{2 \mathrm{~g}}\left({ }^{1} \mathrm{D}\right)$ terms [16]. The band observed at $8900 \mathrm{~cm}^{-1}$ is due to the $\left.{ }^{3} \mathrm{~A}_{2 \mathrm{~g}}\left({ }^{3} \mathrm{~F}\right) \rightarrow{ }^{3} \mathrm{~T}_{2 \mathrm{~g}}{ }^{3} \mathrm{~F}\right)$ transition, while the transition ${ }^{3} \mathrm{~A}_{2 \mathrm{~g}}\left({ }^{3} \mathrm{~F}\right) \rightarrow{ }^{3} \mathrm{~T}_{1 \mathrm{~g}}\left({ }^{3} \mathrm{~F}\right)$ is the one at $15400 \mathrm{~cm}^{-1}$. The shoulder observed at 12250 $\mathrm{cm}^{-1}$ is attributed to the ${ }^{3} \mathrm{~A}_{2 \mathrm{~g}}\left({ }^{3} \mathrm{~F}\right) \rightarrow{ }^{1} \mathrm{E}_{\mathrm{g}}\left({ }^{1} \mathrm{D}\right)$ spin forbidden transition. The values of the crystal field splitting parameter (Dq) and of the B and C Racah parameters have been calculated by taking into account the band positions in the spectrum and using the equations for the energy levels involved in the transitions [16]. These are $\mathrm{Dq}=890 \mathrm{~cm}^{-1}$, $\mathrm{B}=760 \mathrm{~cm}^{-1}\left(74 \%\right.$ of the free $\mathrm{Ni}(\mathrm{II})$ ion, $\left.\mathrm{B}_{\mathrm{o}}\left(\mathrm{Ni}^{2+}\right)=1030 \mathrm{~cm}^{-1}[15]\right)$ and $\mathrm{C}=2700 \mathrm{~cm}^{-1}$. These values are in close agreement with those observed for compounds with $\mathrm{Ni}(\mathrm{II}) \mathrm{d}^{8}$ cations of high spin in slightly distorted octahedral environments [16,17]. 


\subsection{Magnetic Properties}

The thermal evolution of the molar magnetic susceptibility, $\chi_{\mathrm{m}}$, was measured by applying a magnetic field of $0.1 \mathrm{~T}$ (Figure 3). The value of $\chi_{\mathrm{m}}$ decreases when increasing the temperature from 2 to $300 \mathrm{~K}$. The thermal evolution of the inverse of the magnetic susceptibility, $1 / \chi_{\mathrm{m}}$, fits a Curie-Weiss law in the whole temperature range with a Curie constant of $1.33 \mathrm{~cm}^{3} \mathrm{~K} / \mathrm{mol}$ and a Weiss temperature of $-11.4 \mathrm{~K}$. The negative character of the Weiss temperature, in addition to the continuous decrease of the $\chi_{\mathrm{m}} \mathrm{T}$ product with decreasing temperatures - from $1.92 \mathrm{~cm}^{3} \mathrm{~K} / \mathrm{mol}$ at $300 \mathrm{~K}$ to 0.300 $\mathrm{cm}^{3} \mathrm{~K} / \mathrm{mol}$ at $2 \mathrm{~K}$-indicates that the main interactions of the phase are antiferromagnetic.

"Figure 3"

To obtain a better understanding of the magnetic behavior of the phase, the structural characteristics of the compound were evaluated. The minimum distance between two $\mathrm{Ni}^{2+}$ cations is 5.42(2) $\AA$, too large to establish direct magnetic exchange between the metallic centers. The nickel(II) ions in the structure did not share any of the atoms of their coordination sphere with each other. Therefore, the most direct exchange pathways are super-superexchange pathways. There are two pathways along which the magnetic interactions can be propagated: one of them is through one vanadate oxoanion, $\mathrm{J}_{1}$ (Fig. 4), and the other one is through the pyrazine molecules, $\mathbf{J}_{2}$ (Fig. 5). Both pathways have a one-dimensional character. However, the combination of them gives rise to a threedimensional net (Fig. 6). The magnetic behavior observed is the result of the competition between these two pathways.

"Figures 4, 5, and 6"

The average angle of these exchange pathways is $123(2)^{\circ}$, a value different from orthogonality, which explains the predominance of the antiferromagnetic interactions in the phase [18].

Several fittings of the thermal evolution of $\chi_{\mathrm{m}}$ with different theoretical models were conducted, taking into account the structural characteristics described above. The better 
fitting was obtained for a model of isolated chains, whereas the molecular-field approximation [19] had to be applied, making it possible to consider the weaker magnetic coupling between a spin and the neighbors not considered in the initial model. The thermal evolution of the magnetic susceptibility for a chain model was fitted with the Fischer and Dingle equation [20,21]:

$$
\chi=\frac{N g^{2} \beta^{2} S(S+1)}{3 k T} \cdot \frac{1-u}{1+u},
$$

where $u=T / T_{o}-\operatorname{coth}\left(T_{o} / T\right)$ and $T_{o}=2 J S(S+1) / k$.

The magnetic susceptibility obtained from this equation was corrected by the following expression:

$$
\chi_{i}^{\prime}=\frac{\chi_{i}}{1-\left(2 z J / N g^{2} \beta^{2}\right) \chi_{i}}+\chi_{\mathrm{TIP}}
$$

where $\chi_{\text {TIP }}$ is the temperature-independent paramagnetism term.

In this way, an optimal fit of the experimental curve was obtained with $g=2.31$, $J / k=-5.3, z J^{\prime} / k=-5.5$ and $\chi_{\mathrm{TIP}}=7.310^{-5}$ (Figure 3 ). The negative character of the $J$ confirms that the main interactions are antiferromagnetic. However, the high value obtained for $z J^{\prime} / k$, higher than the $10 \%$ of $J / k$, indicates that the theoretical model is not absolutely correct, although it is a good approximation to the real magnetic behavior of the compound. The fact that a reasonable fitting was obtained for a chain model implies that one of the proposed magnetic exchange pathways is effective, while the other one is not. A neutron powder diffraction study would be necessary to corroborate this fact. 


\section{Acknowledgements}

This work has been financially supported by the "Ministerio de Educación y Ciencia" (MAT2007-60400) and the "Gobierno Vasco: Grupo Consolidado de Apoyo al Sistema Universitario Vasco" (Ref. IT-177-07). The authors thank the technicians of SGiker, who were financed by the National Program for the Promotion of Human Resources within the National Plan of Scientific Research, Development and Innovation, "Ministerio de Educación y Ciencia" and "Fondo Social Europeo", for performing the measurements. Edurne S. Larrea thanks the UPV/EHU for funding. 


\section{References}

[1] G. Kickelbick, "Hybrid Materials. Synthesis, Characterization and Applications" (2007) Wiley VCH Verlag GmbH \& Co. KGaA, Weinheim, Germany.

[2] (a) S.M: Cohen, Curr. Opin. Chem. Biol. 11 (2007) 115-120; (b) P. Horcajada, C. Serre, M. Vallet-Regí, M. Sebban, F. Taulelle, G. Férey, Angew. Chem. Int. Ed. 45 (2006), 5974-5978; (c) M. Vallet-Regí, F. Balas, D. Arcos, Angew. Chem. Int. Ed. 46 (2007), 7548-7558; (d) M.D. Rowe, D.H. Thamm, S.L. Kraft, S.G. Boyes, Biomacromolecules 10 (2009) 983-993.

[3] (a) G.J. Halder, C.J. Kepert, B. Moubaraki, K.S. Murray, J.D. Cashion, Science 298 (2002) 1762-1765; (b) G. Lu, J.T. Hupp, J. Am. Chem. Soc. 132(23) (2010) 7832-7833.

[4] (a) P.M. Forster, A.K. Cheetham, Top. Catal. 24 (2003) 79-86; (b) D. Farrusseng, S. Aguado, C. Pinel, Angew. Chem. Int. Ed. 48 (2009) 7502-7513; (c) J.Y. Lee, O.K. Farha, J. Roberts. K.A. Scheidt, S.B.T. Nguyen, J.T. Hupp, Chem. Soc. Rev. 38 (2009) 1450-1459.

[5] (a) P.J. Hagrman, D. Hagrman, J. Zubieta, Angew. Chem. Int. Ed. 38 (1999) 26382684; (b) M.I. Khan, J. Solid State Chem. 152 (2000) 105-112.

[6] M. Schindler, F. C. Hawthorne, W. H. Baur, Chem. Mater. 12 (2000) 1248-1259.

[7]P. Y. Zavalij, M. S. Whittingham, Acta Crystallogr., Sect. B 55 (1999) 627-663.

[8] (a) M. Schindler, F. C. Hawthorne, W. H. Baur, Can. Mineral. 38 (2000) 14431456; (b) J. Livage, Coord. Chem. Rev. 178-180 (1998) 999-1018; (c) R. Fernández de Luis, M.K. Urtiaga, J.L. Mesa, T. Rojo, M.I. Arriortua, J. Alloy Compd. 480 (2009) 5456.

[9] (a) E.S. Larrea, J.L. Mesa, J.L. Pizarro, J. Rodríguez-Fernández, M.I. Arriortua, T. Rojo, Eur. J. Inorg. Chem. (2009) 3607-3612; (b) C. Sun, E. Wang, D. Xiao, H. An, L. Xu, J. Mol. Struct. 840 (2007) 53-58.

[10] (a) Y.-Q. Jiang, Z.-H. Xu, Z.-X. Xie, J. Coord. Chem. 61 (2008) 1575-1581; (b) R. Fernández de Luis, M.K. Urtiaga, J.L. Mesa, K. Vidal, L. Lezama, T. Rojo, M.I. Arriortua, Chem. Mater. 22 (2010) 5543-5553; (c) R. Fernández de Luis, M.K. Urtiaga, J.L. Mesa, L. Lezama, T. Rojo, M.I. Arriortua, New J. Chem. 32 (2008) 1-8; (d) R. Fernández de Luis, M.K. Urtiaga, J.L. Mesa, A.T. Aguayo, T. Rojo, M.I. Arriortua, CrystEngComm 12 (2010) 1880-1886.

[11]E.S. Larrea, J.L. Mesa, J.L. Pizarro, M.I. Arriortua, T. Rojo, J. Solid State Chem. 180 (2007) 1149-1157.

[12] P. Román, J.M. Gutierrez-Zorrilla, J. Chem. Educ. 62 (1985) 167.

[13] H. Müeller-Buschbaum, M. Kobel, Z. Anorg. Allg. Chem. 596 (1991) 23-28.

[14] J.A.A. Ketelaar, Z. Kristallogr., Kristallgeom., Kristallphys., Kristallchem. 95 (1936) 9.

[15] Y. Tanabe, S. Sugano, J. Phys. Soc. Japan 9 (1954) 753-766.

[16] A.B.P. Lever, "Inorganic Electronic Spectroscopy" (1984) Elsevier Science Publishers B.V., Ámsterdam, Netherland.

[17] J. Escobal, J.L. Pizarro, J.L. Mesa, M.I. Arriortua, T. Rojo, J. Solid State Chem. 154 (2000) 460-465. 
[18] J.B. Goodenough, "Magnetism and the Chemical Bond" (1963) Inrscience, New York.

[19] R.L. Carlin, "Magnetochemistry" (1986) Springer-Verlag, Berlin Heidelberg. [20] M.E. Fischer, Am. J. Phys. 32 (1964) 343-346.

[21] R. Dingle, M.E. Lines, S.L. Holt, Phys. Rev. 187 (1969) 643-648. 


\section{Figure Captions:}

Figure 1 Rietveld analysis of the X-ray powder diffraction pattern of $\mathrm{Ni}_{3}\left(\mathrm{C}_{4} \mathrm{H}_{4} \mathrm{~N}_{2}\right)_{3}\left(\mathrm{~V}_{8} \mathrm{O}_{23}\right)$.

Figure 2 Thermal evolution of the diffraction patterns of $\mathrm{Ni}_{3}\left(\mathrm{C}_{4} \mathrm{H}_{4} \mathrm{~N}_{2}\right)_{3}\left(\mathrm{~V}_{8} \mathrm{O}_{23}\right)$ between room temperature and $500{ }^{\circ} \mathrm{C}$.

Figure 3 Thermal evolution of $\chi_{\mathrm{m}}$ and $\chi_{\mathrm{m}} \mathrm{T}$ at $0.1 \mathrm{~T}$ for $\mathrm{Ni}_{3}\left(\mathrm{C}_{4} \mathrm{H}_{4} \mathrm{~N}_{2}\right)_{3}\left(\mathrm{~V}_{8} \mathrm{O}_{23}\right)$. The solid line represents the fit of the magnetic behavior with a corrected model for isolated chains.

Figure 4 Drawing of the super-superexchange pathway $\mathrm{J}_{1}$ (green bonds).

Figure 5 Drawing of the super-superexchange pathway $\mathbf{J}_{2}$ (deep red bonds).

Figure 6 Schema of the combination of the exchange pathways $J_{1}$ and $J_{2}$. 


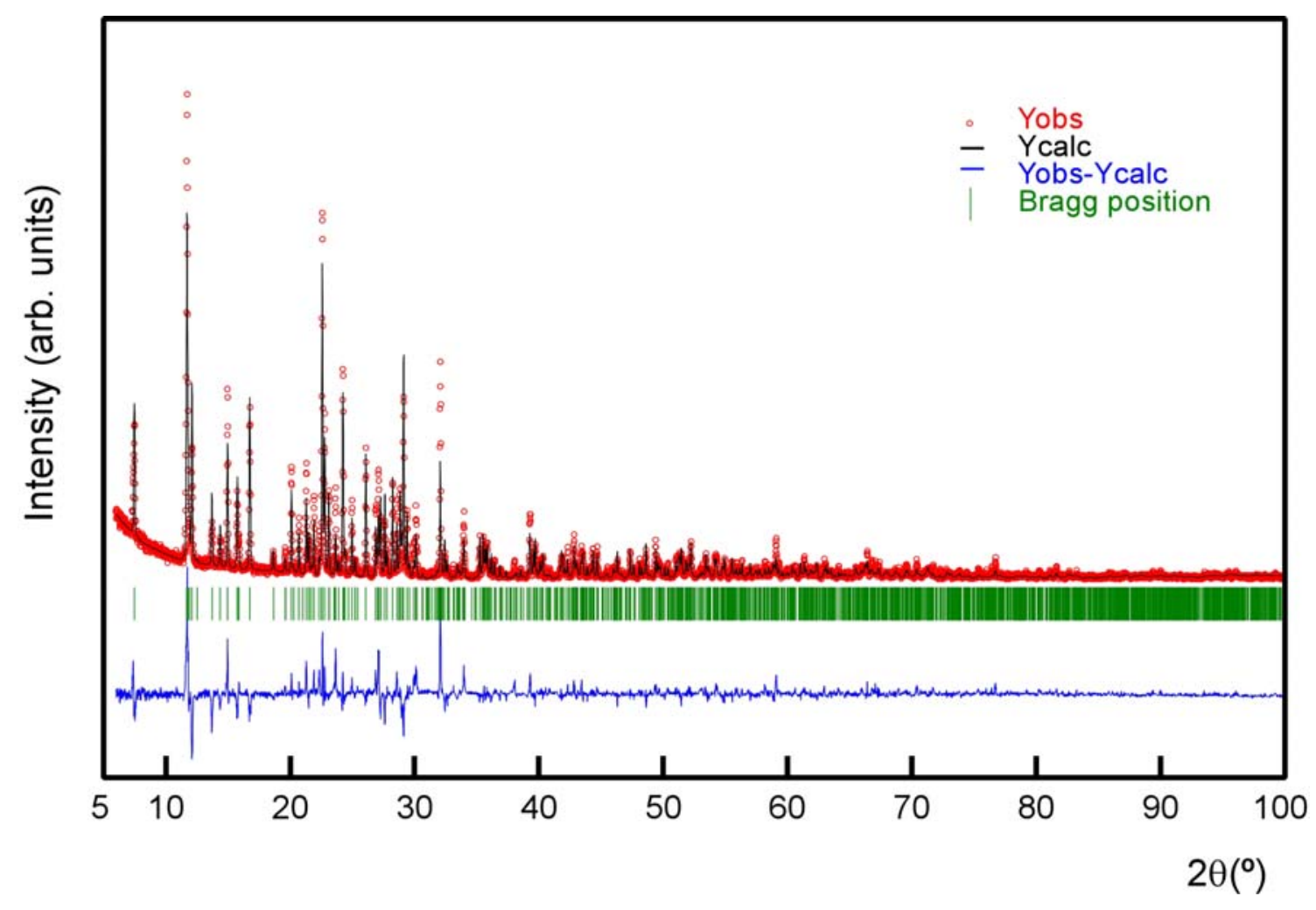

Figure 1 


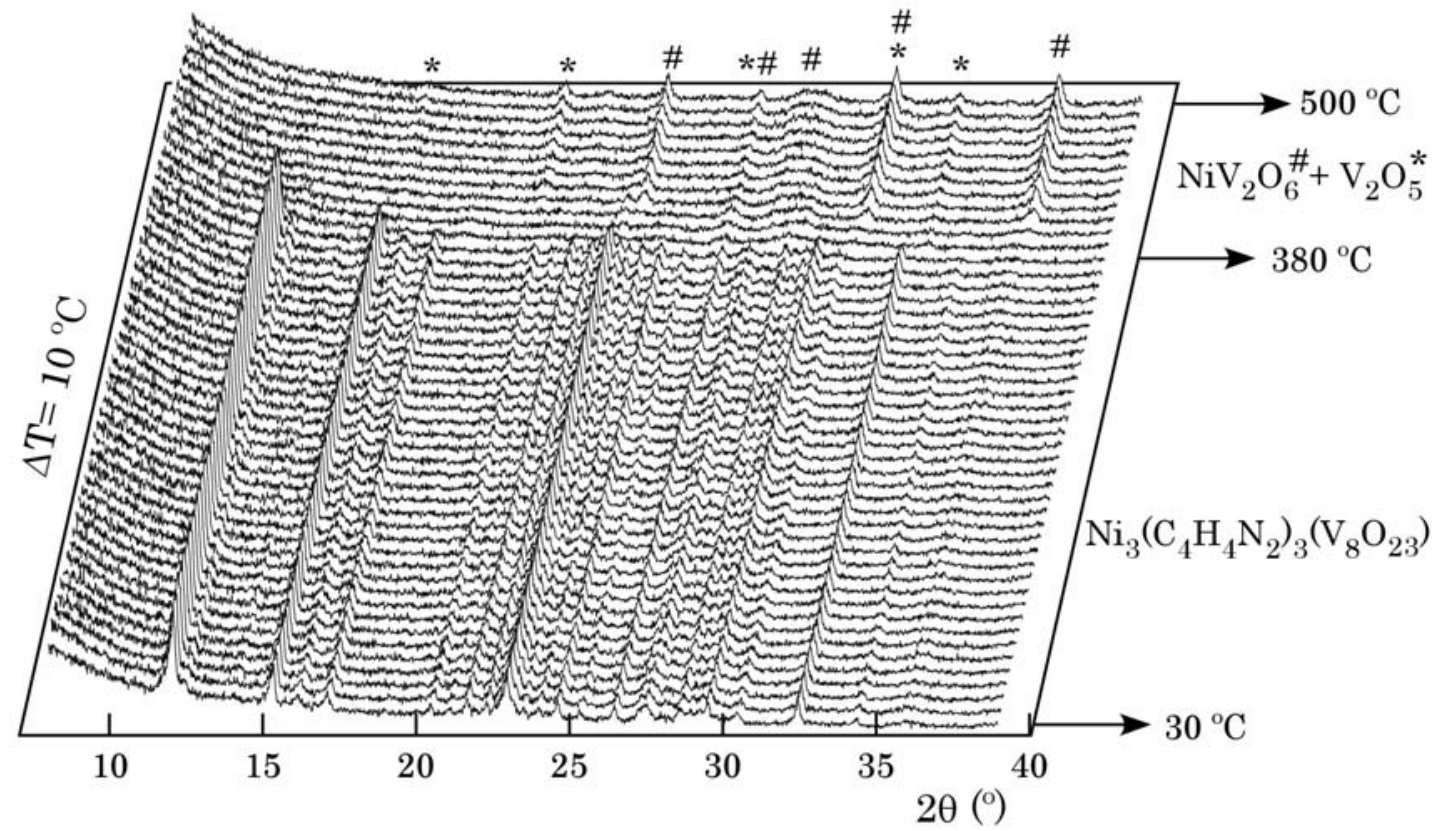

Figure 2 


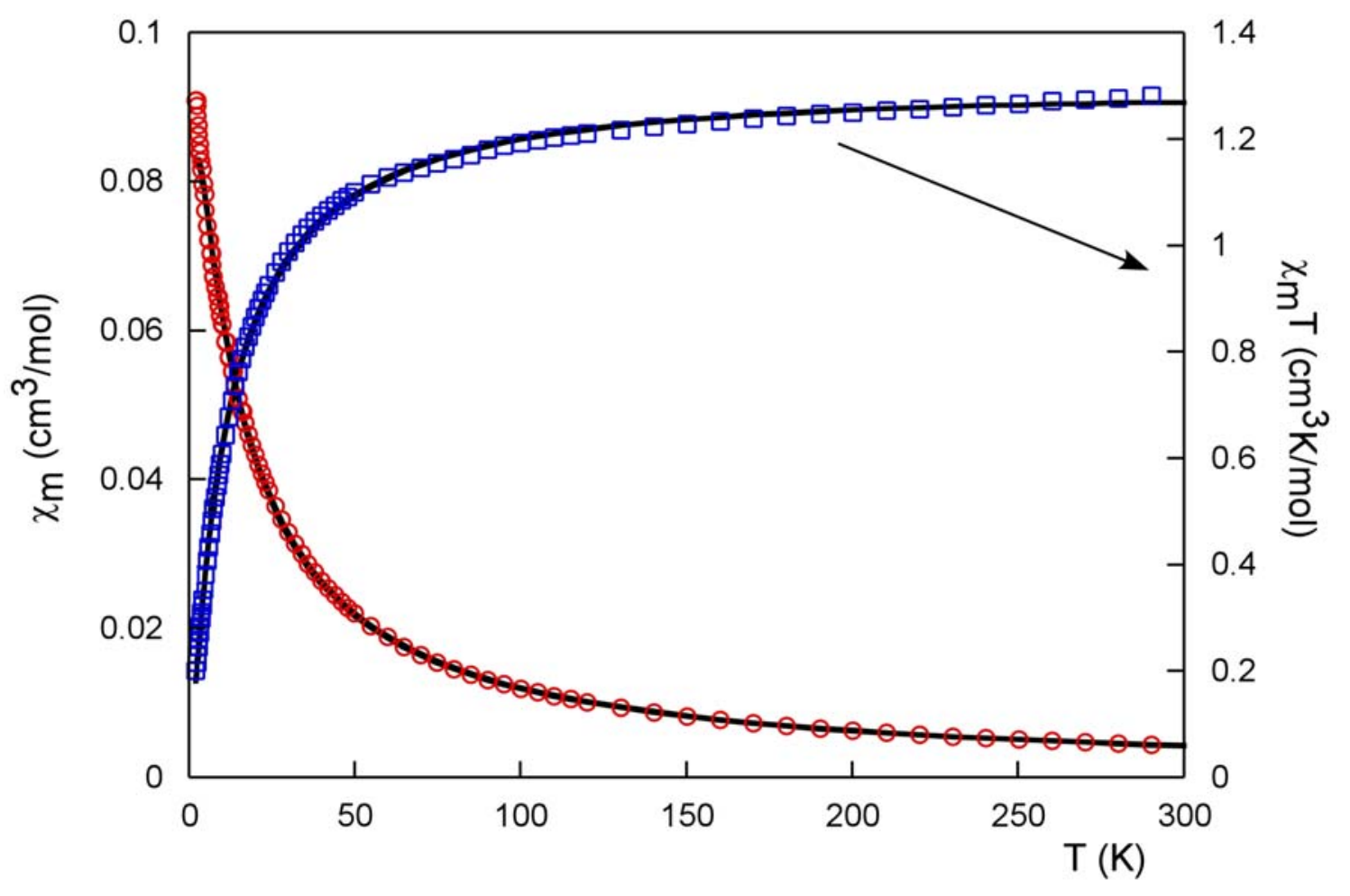

Figure 3 


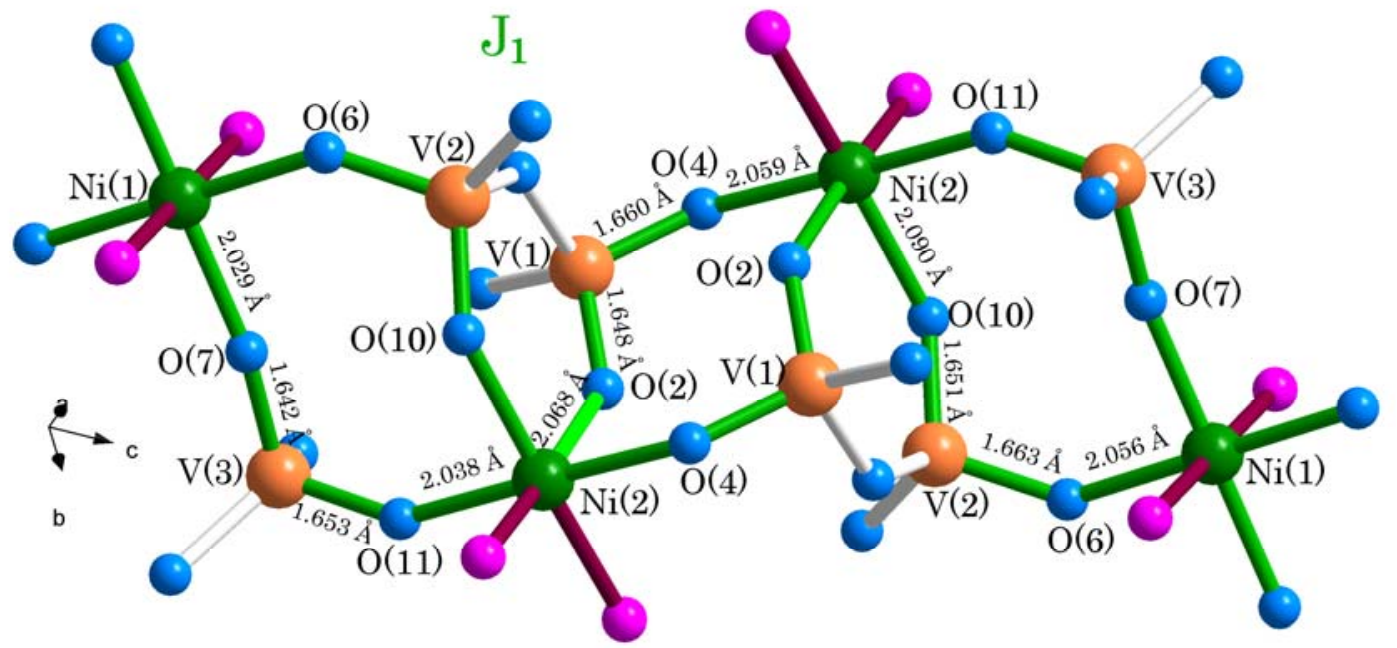

Figure 4 


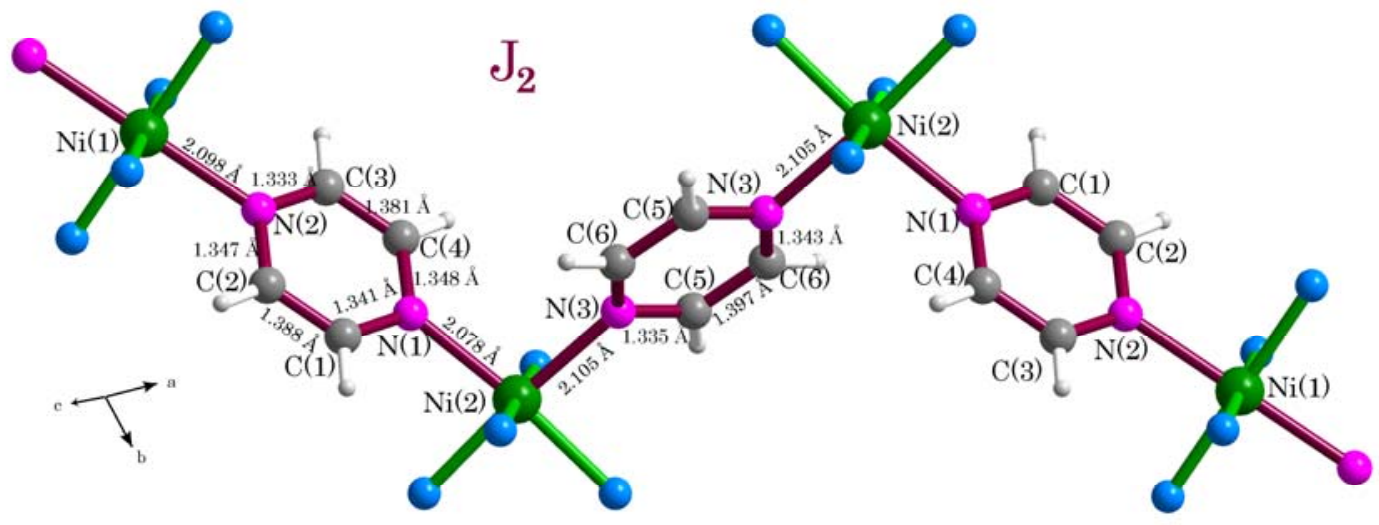

Figure 5 


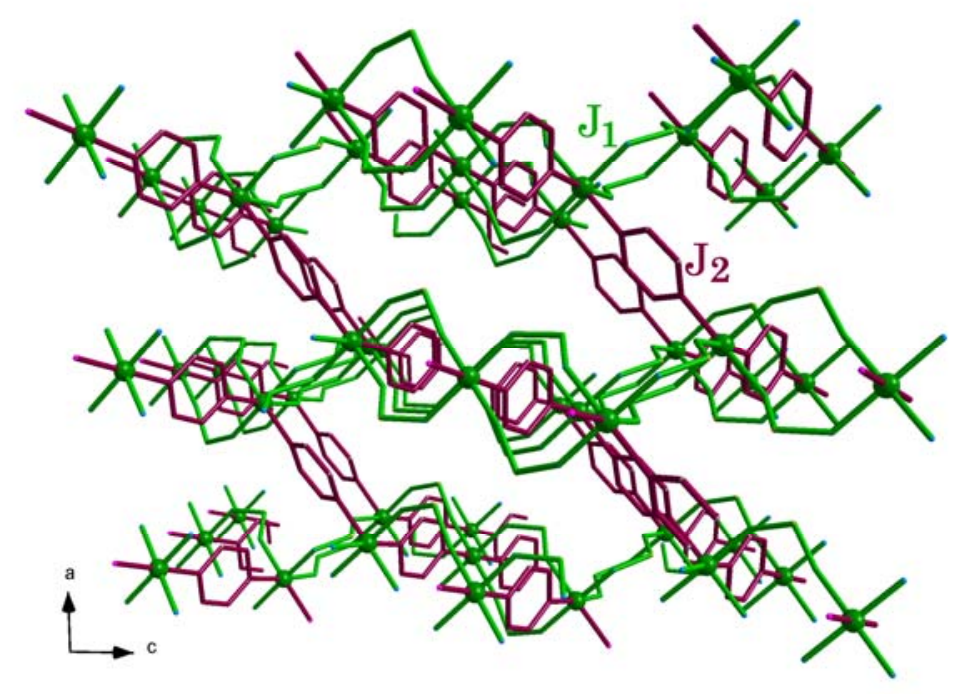

Figure 6 
GRAPHICAL ABSTRACT

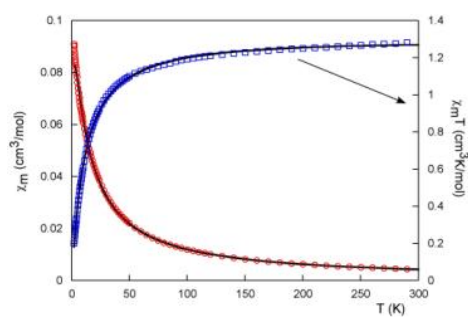

Magnetic fit to a chain model 
Research Highlights

- A novel Inorganic-organic hybrid vanadate of nickel(II) cooordination complex with pyrazine has been synthetized hydrothermally

- The thermal and spectroscopic behavior has been studied

- The compound shows AFM interactions which has been fitted to a magnetic model of lineal chains 